\title{
Research trends and hotspots of high tibial osteotomy in two decades (from 2001 to 2020): a bibliometric analysis
}

Haitao Zhang ${ }^{1}$, Yinuo Fan ${ }^{1}$, Rui Wang ${ }^{1}$, Wenjun Feng ${ }^{2}$, Jinlun Chen ${ }^{2}$, Peng Deng ${ }^{2}$, Xinyu Qi ${ }^{2}$, Pengcheng Ye ${ }^{2}$, Yijin Li', Jiahao Li ${ }^{1}$, Jianchun Zeng ${ }^{2}$ and Yirong Zeng ${ }^{2 *}$

\begin{abstract}
Background: The purpose of this study is to comprehensively analyze the global application trend of high tibial osteotomy (HTO) and identify promising research hotspots of HTO based on bibliometrics and visual analysis.

Methods: Publications (articles and reviews) related to HTO from 2001 to 2020 were retrieved from the Web of Science Core Collection database (WOSCC). The country, institution, year, author, journal, average citations per item, $\mathrm{H}$ index, title, abstract, keywords of publication, and the top 10 cited articles were extracted and analyzed in detail. The VOSviewer software was used to analyze theco-occurrence of keywords to predict the hotspots of HTO.

Results: A total of 1883 articles were included. In the past 20 years, the number of HTO articles has shown an increasing trend in general. The top 3 countries (the USA, Germany, and South Korea) accounted for $49.547 \%$ of all articles published. The USA has the largest number of publications. The University of Western Ontario is the largest contributor. The Knee Surgery Sports Traumatology Arthroscopy is the most influential journal. Professors Saito T and Imhoff $\mathrm{AB}$ are the leading scholars who made great achievements in the HTO field. The research direction can be divided into the following 5 clusters: "prognosis and outcome", "HTO combined with cartilage restoration techniques", "animal experimental research", "study on bone union and plate fixation at osteotomy", and "surgical technique research".

Conclusion: In terms of the trend of previous years, an increasing number of literatures related to HTO will be published in the future. The USA is a world leader in the field of HTO. South Korea presented great potential in this area. HTO combined with cartilage restoration techniques, postoperative prognosis and outcome, and surgical technique research may be the future hotspots in the field of HTO research.
\end{abstract}

Keywords: Bibliometric, Research trends, Hotspots, High tibial osteotomy

\footnotetext{
* Correspondence: zeng1966zeng@126.com

${ }^{2}$ Department of Orthopaedics, The First Affiliated Hospital of Guangzhou

University of Chinese Medicine, Jichang Road 16\#, District Baiyun,

Guangzhou 510405, Guangdong, China

Full list of author information is available at the end of the article
} 


\section{Introduction}

Knee osteoarthritis (KOA) is a degenerative bone and joint disease that seriously affects the life quality of patients [1, 2]. Currently, the mainstream surgical approach for the treatment of knee osteoarthritis includes total knee arthroplasty (TKA), unicompartmental knee arthroplasty (UKA), and high tibial osteotomy (HTO). Although TKA and UKA have received a positive evaluation in elderly patients, HTO appears to be a more sensible option for many younger patients with high functional activity needs [3,4]. As a mature method of "knee preservation," HTO has been widely used in the treatment of unicompartmental knee osteoarthritis. The operation principle of HTO is to transfer the pressure load in unicompartment by adjusting the force line of the lower extremities so as to relieve pain, restore knee joint function, and prolong knee joint life [5]. Numerous studies have shown that HTO has been proven to be a reliable treatment with good short- and medium-term efficacy for KOA after years of clinical practice [6-8]. In recent years, a growing number of orthopedic surgeons have shown great interest in HTO surgery due to a substantial increase in the number of patients with KOA [9].

However, to the best of our knowledge, the recent research status and future research hotspots of HTO have not been well studied. In the context of the high profile of HTO, it is particularly meaningful to understand the global status quo of the field and predict future research hotspots. Bibliometrics is a multi-system discipline that integrates mathematics, statistics, philology, and other disciplines. Its advantage lies in the qualitative and quantitative evaluation of specific research areas based on multi-disciplines [10]. At present, bibliometrics has been extensively applied on numerous medical fields as a burgeoning method [11]. This study systematically analyzed the relevant literatures of HTO from 2001 to 2020 by using the Web of Science (WOS) database and VOSview software to provide a more comprehensive understanding of the global application trend and identify promising research direction in the future of HTO.

\section{Methods}

\section{Data source and search strategies}

The Web of Science Core Collection (WOSCC) is recognized as the most suitable online database for bibliometric analysis. We select the "Advanced search" function in the WOSCC online database and enter keywords to obtain the relevant literature of HTO from January 2001 to May 30, 2020 (the last 20 years). Document retrieval and export should be completed within 1 day to avoid bias caused by continuous database update. The retrieval strategy of this study was as follows: (Ts = high tibial osteotomy), refined by, document type (article OR review), and language (English).

\section{Data collection}

All literature retrieval and data extraction were completed independently by two authors (Zhang and Fan) with familiar literature retrieval background. When they disagree, the differences are fully discussed until they reach an agreement. The data is saved in the TXT document format by using the built-in "create citation report" and "analyze search results" functions in WOSCC and in turn is imported into Microsoft Excel 2019 for further collation. The data include publishing country or region, institution, year, author, source journal, average citation times, $\mathrm{H}$ index, title, abstract, and keyword. The top 10 most-cited literatures were collected and preliminarily reviewed and analyzed. The relevant information of the top 10 most-cited literatures includes the first author, topic, citations, journal, and journal impact factor (IF). IF is obtained from the 2018 version of Journal Citation Reports (JCR).

\section{Bibliometric and visualized analysis}

The world distribution map of HTO-related research and the forecast map of quantity growth trend of HTO publications are produced by using Microsoft Excel 2019. The citation frequency of the literature reflects the degree to which the article is recognized by scholars. $\mathrm{H}$ index is a qualitative and quantitative comprehensive index reflecting the academic level of scholars. This means that the citation frequency and the $\mathrm{H}$ index of the literature can also be extended to assess the academic contribution of a country, institution, journal, or author. Therefore, Microsoft Excel 2019 is used to draw a combination chart of the total number, $\mathrm{H}$ index, and average citations per item of publications, according to the grouping of countries, institutions, journals, and authors. VOSviewer (Van Eck and Walt-man, Leiden University, Leiden, The Netherlands) is a universally used visual tool supported by Java [12]. The downloaded TXT file is imported into VOSviewer1.6.15 for literature co-citation analysis and keyword co-occurrence analysis. In the visualization analysis figure, the larger the label, the more important the label, and the thicker the line between nodes indicate the closer relationship between the two nodes connected by the line.

\section{Results}

Analysis of publication trend in recent two decades

A total of 2049 publications related to HTO were searched, and 1883 met the criteria from 2001 to 2020 (Fig. 1). Figure 2a shows that although the number of publications related to HTO has fluctuated slightly over the past 20 years, it has presented an overall growth trend. The year 2019 (225 papers) is the peak of the number of literatures. It is predicted that the number of 


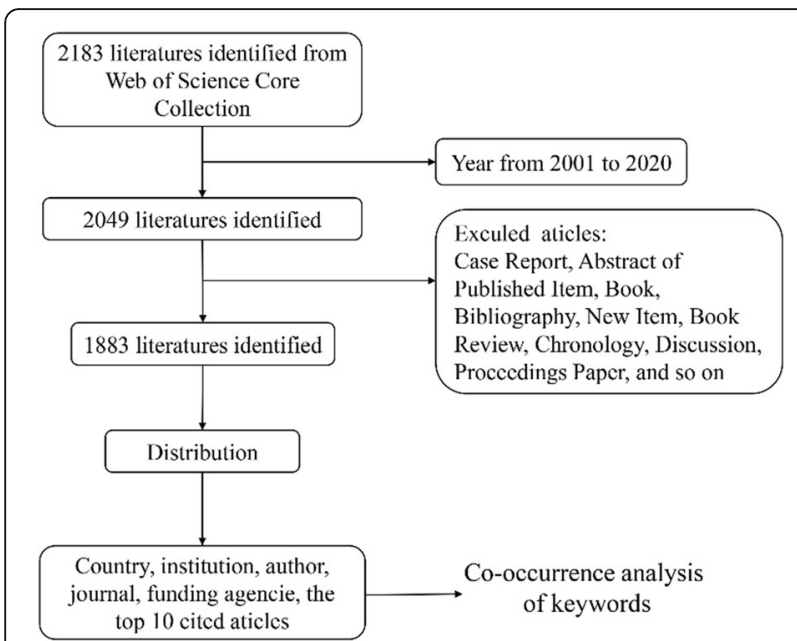

Fig. 1 Flow chart of literature filtering included in this study

publications will reach 250 by 2025 according to the curve model.

\section{Distribution and contribution of the country (region)}

Overall, the included literatures come from 63 different countries or regions (Fig. 2b). Figure 2c shows the number of publications from the USA, Germany, and South Korea over a 20 -year period. The USA $(450,23.974 \%)$ is the country with the largest number of articles in the field of HTO research. Germany ranked second (255, $13.586 \%)$. In third place is South Korea $(225,11.987 \%)$. The top three countries accounted for $49.547 \%$ of all articles (Fig. 2d).

In addition, the USA ranked first in the H Index (58), followed by Germany (44), while France (27) ranked third. Surprisingly, France overtook the USA in the average citations per item, while the USA (26.58) and Germany (26.77) ranked second and third with almost the same number.

\section{Highly contributive institutions on HTO}

Figure 3a shows the 10 organizations that have contributed the most in the field of HTO. Among them, the University of Western Ontario from Canada published the most articles (48 papers). This was followed by Seoul National University SNU (46 papers) and Inje University (44 papers) from South Korea. However, the top three institutions of the $\mathrm{H}$ index are HOSP SPECIAL SURG (USA, 20), University of Western Ontario (USA, 19), and Hannover Medical School (Germany, 18). Regarding the average citation frequency, the Hannover Medical School (37) ranked first, followed by the Technical University of Munich (Germany, 28.95) and the University of Western Ontario (28.63).

\section{Highly contributive authors on HTO}

Saito T $(35, \mathrm{H}$ index $=16)$ and Imhoff $\mathrm{AB}(35, \mathrm{H}$ index = 18) rank in the top two with almost equal number of posts and $\mathrm{H}$ index. Although Birmingham TB's articles are cited more frequently (36.08), the number (25) is much lower than the previous two authors (Fig. 3b).

\section{Highly contributive journals on HTO}

The Knee Surgery Sports Traumatology Arthroscopy has published the most HTO surgery papers (IF $=3.149$, 281), followed by the Knee $(1.762,122)$ and the American Journal of Sports Medicine $(6.093,85)$. Knee Surgery Sports Traumatology Arthroscopy (39) has the highest H index. However, the Journal of Bone and Joint Surgery American Volume (29) and Arthroscopy: the Journal of Arthroscopic and Related Surgery (27) which publicated smaller number papers have higher $\mathrm{H}$ index. A similar situation also appears in the average citation frequency (Fig. 3c).

\section{Distribution of highly contributive funding agencies}

The top 10 funding organizations are shown in Table 1, including 3 from the USA, 4 from South Korea, and 2 from Germany.

\section{Characteristics of the top 10 HTO articles}

As for the top 10 articles with total citation frequency, the study by Zhang et al., published in the Osteoarthritis and Cartilage in 2008, had the most total citation frequency (1569). Its total citation frequency is far higher than that of other articles. Of the ten articles, three were published in Osteoarthritis and Cartilage and two in Knee Surgery Sports Traumatology Arthroscopy (Table 2).

\section{Hotspots analysis of HTO surgery}

The co-occurrence analysis of keywords is a significant method to identify the hotspots of HTO research. The principle is to identify the importance of keywords by calculating the number of times that keywords appear repeatedly in all the titles and abstracts of included literatures. Setting the counting method to binary counting, the minimum number of recurring keywords is 10 . The 692 keywords that reached the threshold are shown in Fig. 4a and are divided into five clusters. These five categories represent the main research directions in the field of HTO during the past 20 years. The five clusters are "HTO postoperative prognosis and outcome" (cluster 1, purple), "HTO combined with cartilage restoration techniques" (cluster 2, light blue), "Animal experimental research" (cluster 3, dark blue), "Study on bone union and plate fixation at osteotomy" (cluster 4, green), and "Surgical technique research" (cluster 5, yellow) (Fig. 4 a, c). In cluster 1, the most striking keywords are total knee arthroplasty, WOMAC, reconstruction, long-term outcome, KOOS, 


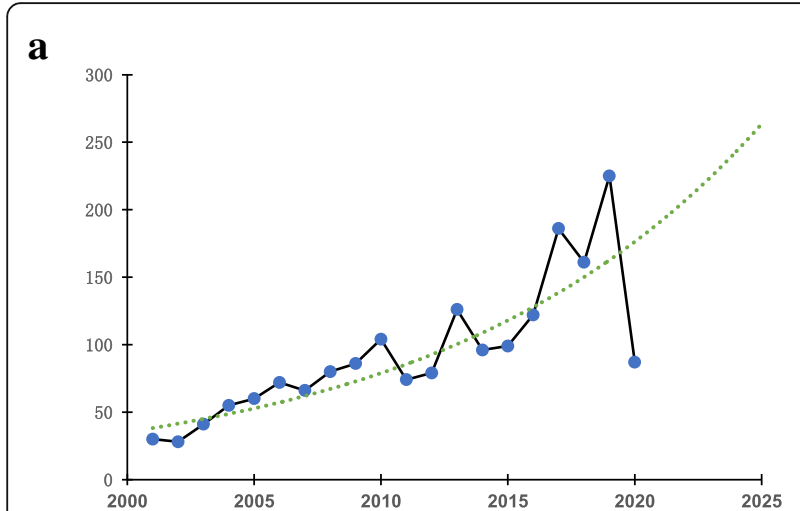

b

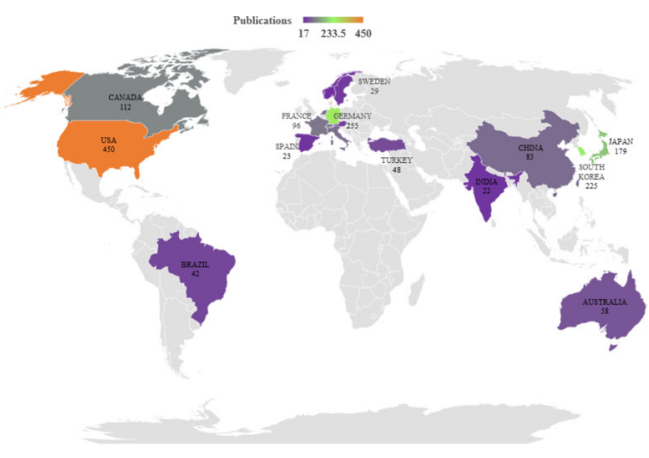

c

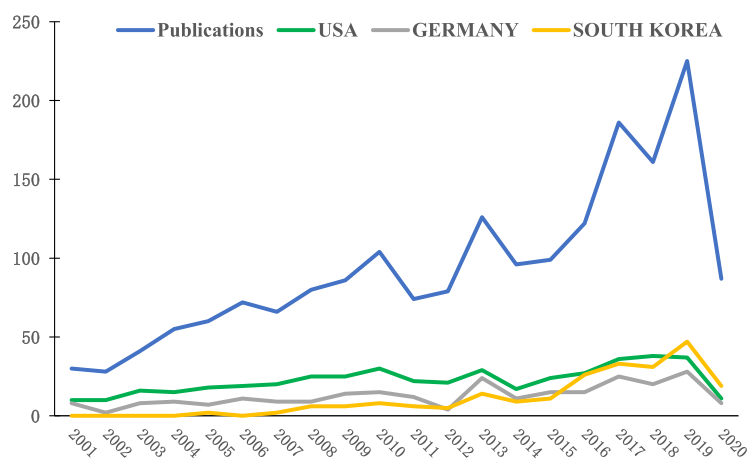

d $\mathrm{H}$ index $=$ Average citations per item $\longrightarrow$ Publications

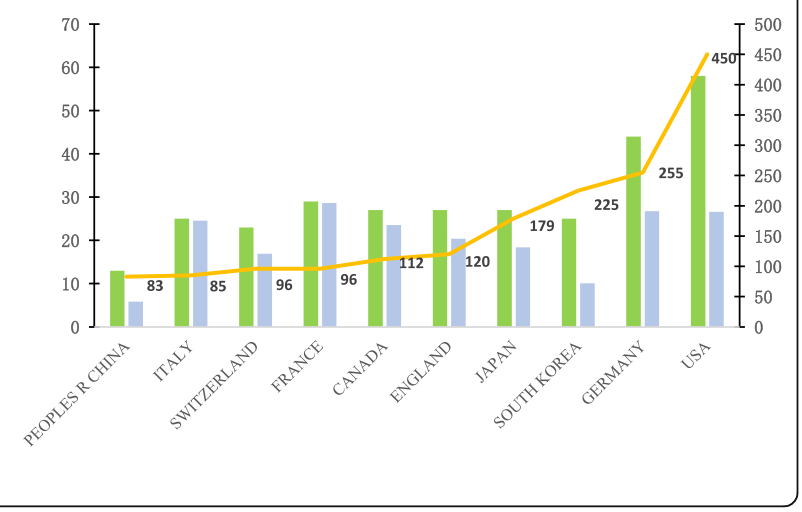

Fig. 2 a Curves: growth trends of accumulated number of publications on HTO worldwide from 2001 to 2020. b Distribution of HTO research in the world map. $\mathbf{c}$ The number of publications from the USA, Germany, and South Korea over a 20-year period. $\mathbf{d}$ The total number of articles published, the $\mathrm{H}$ index, and the average citations per item in the top 10 countries

VAS, and functional score. In cluster 2, the more common keywords are knee osteoarthritis, cartilage, efficacy, and stem cell. In cluster 3 , the keywords with the most repetition are animal, rat, rabbit, dog, and stifle. In cluster 4, the most popular keywords are fixation, stability, plate, bone, healing, and osteotomy gap. In cluster 5 , the most prominent keywords are open wedge high tibial osteotomy, proximal tibial, closed wedge, joint line convergence angle, and knee alignment.

An overlap visual rainbow diagram (Fig. 4 b) is drawn based on the approximate year in which the keyword appears, and the color varies with the timeline (20122018). Blue and purple nodes appear later than yellow and red nodes, meaning that red and yellow nodes are hot keywords. As can be seen from the figure, although most of the studies before 2014 focused on cluster 3 and cluster 4, after 2016, most of the hot keywords concentrated on cluster 1 , cluster 2 , and cluster 5 .

\section{Discussion}

In this study, we systematically studied the HTO surgery nearly 20 years of the present situation and development trend by combining with the bibliometrics and visualization analysis. We analyzed countries, institutions, journals, and authors that have made high contributions to this field. In addition, we have discovered the direction of rapid development that may become a hotspot in the future to attract scholars, which will provide convenience and shortcuts for later research. Over the past 20 years, although the number of articles on HTO surgery has declined in 2011, 2012, 2014, and 2015, it has shown an overall growth trend. This may be due to the rapid increase in the number of patients with knee osteoarthritis with the aging of the population, and the continuous penetration of the concept of "knee protection" has prompted an increasing number of chief surgeons and patients to prefer HTO surgery. Moreover, we predict that the trend in the next 5 years or even 10 years will have an even more significant growth.

No matter in terms of the number of publications, $\mathrm{H}$ index, and average citation frequency, the USA is a world leader in the field of HTO. This trend shows that the USA has the highest literature quality and influence and has made the greatest contribution to this field. This is mainly attributed to the USA having the most advanced medical research level and the strongest economic strength around the world. Besides, Germany and 


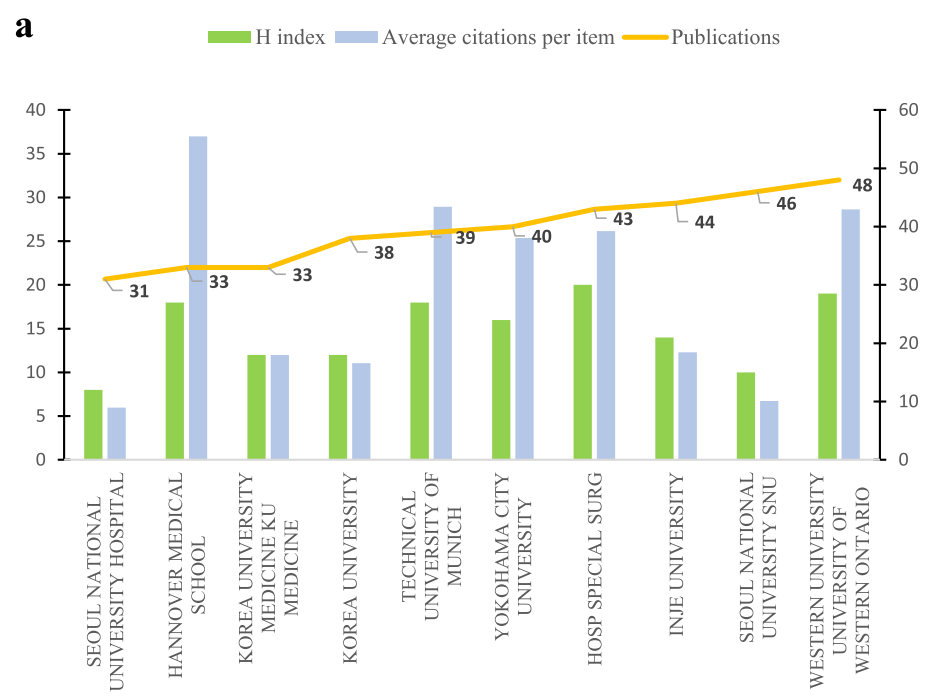

b H index Average citations per item $\longrightarrow$ Total of Publications

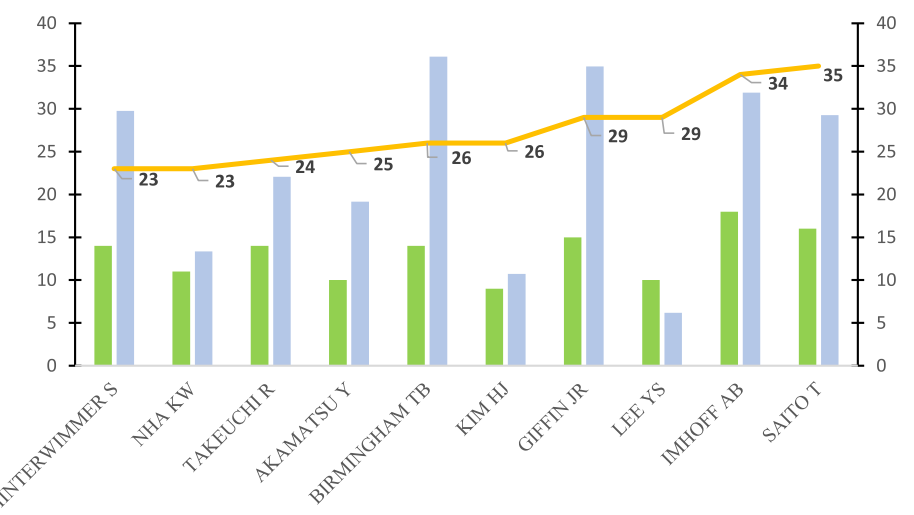

c

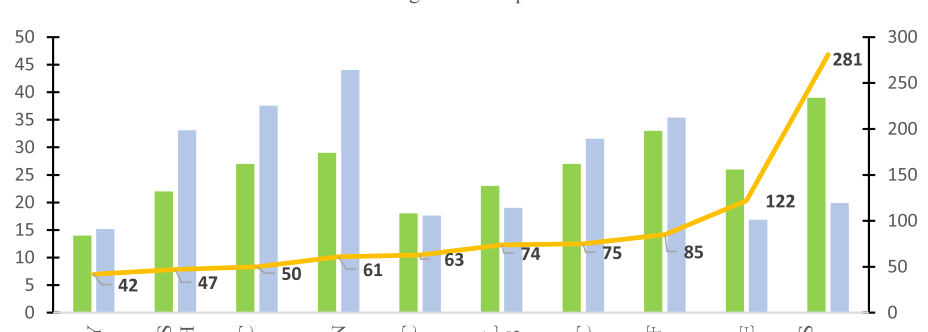

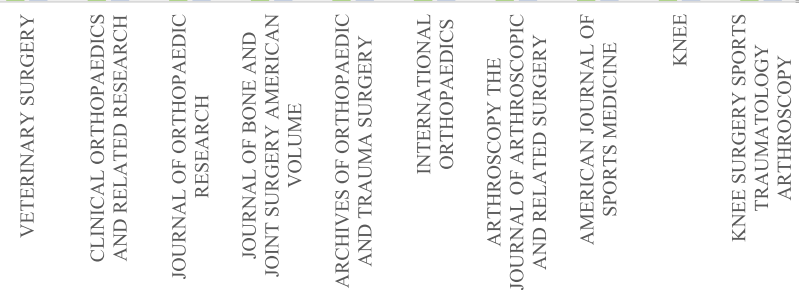

Fig. 3 A combination chart of the total publications, $\mathrm{H}$ index, and average citations per item. a About institutions. b About authors. c About journals 
Table 1 The top 10 related funding agencies

\begin{tabular}{lll}
\hline Funding agency & Number & $\%$ \\
\hline National Institutes of Health (NIH) USA & 37 & 1.971 \\
United States Department of Health Human Services & 37 & 1.971 \\
Canadian Institutes of Health Research (CIHR) & 25 & 1.332 \\
Arthrex & 23 & 1.225 \\
NIH National Institute of Arthritis Musculoskeletal Skin Diseases (NIAMS) & 20 & 1.066 \\
National Natural Science Foundation of China & 17 & 0.906 \\
Smith Nephew & 16 & 0.852 \\
German Research Foundation (DFG) & 14 & 0.746 \\
Canada Research Chairs & 13 & 0.693 \\
Arthrex Inc. & 12 & 0.639 \\
\hline
\end{tabular}

South Korea have made outstanding contributions in this field. It is worth mentioning that the number of publications of South Korea surpassed the USA and Germany in 2019. This implies that South Korea has developed rapidly in the HTO field and is a country with great potential (Fig. 2c).

The University of Western Ontario from Canada has published the most articles, with its $\mathrm{H}$ index and average cited frequency also ranking second. Obviously, the University of Western Ontario is the biggest contributor in the field of HTO. Furthermore, the second- and third-highest number of publications are from South Korea, another sign that the country is growing rapidly in this field. However, in terms of $\mathrm{H}$ index and average citation frequency, one institution in the USA and two institutions in Germany rank top.

As for author contributions, the $\mathrm{H}$ index and average citation frequency of the top 10 authors with the highest number of publications were similar, except for Lee YS. Therefore, the number of publications can be considered to be an important criterion for evaluating the contribution of authors. Saito $\mathrm{T}$ and Imhoff $\mathrm{AB}$ are the leading scholars in the field of HTO according to the number of publications. Paying attention to their research direction and achievements will help us to grasp the latest trends in this field.

Knee Surgery Sports Traumatology Arthroscopy has become the most influential journal in the field of HTO with the largest number of articles, the highest $\mathrm{H}$ index, and the average cited frequency. Nevertheless, although Knee has the second largest number of publications, its $\mathrm{H}$ index is low. This may be related to the large number of annual articles published by Knee.

The top two funding institutions are all from the USA, which explains one of the reasons why the USA is the largest contributor in this field. Meanwhile, it also suggests that funding plays a vital role in the development of a research field.
Detailed analysis of co-occurrence keyword results will help us grasp the HTO surgery for the future of the research hotspot.

Cluster 1 is "HTO postoperative prognosis and outcome." HTO is suitable for most young patients due to its advantage of avoiding or delaying total knee arthroplasty $[4,13]$. As a surgical method to preserve the knee joint, the postoperative result is a topic of great concern to both doctors and patients [14]. Generally speaking, many kinds of rating scales can be used to measure knee joint function, including KOOS, VAS, and WOMAC score. Multiple studies have confirmed that HTO has good short- and medium-term efficacy [15-17]. However, inevitably, there are still some patients who have to undergo TKA on account of the deterioration of joint degeneration. This involves a controversial issue of widespread concern currently, whether the failure of HTO will affect the efficacy of TKA. A meta-analysis showed that compared with primary TKA, the conversion of HTO to TKA after failure would prolong the operation time, affect the postoperative function, and increase the risk of infection and revision [18]. Undoubtedly, the prognosis of HTO surgery has always been a research direction of interest to scholars, because it is directly related to the life quality of patients.

Cluster 2 is "HTO combined with cartilage restoration techniques." Cartilage repair technology enriches the treatment of young patients with knee osteoarthritis [19]. Common cartilage restoration techniques include microfracture with abrasion of articular cartilage and autologous chondrocyte transfer. Cartilage restoration techniques improve pain relief after HTO, while HTO support repairs articular cartilage by adjusting the line of force [20]. This collaborative relationship stimulated interest from orthopedic surgeons. Before the birth of cartilage restoration techniques, some scholars believe that the effect of HTO was poor. Many recent studies have shown that HTO combined with cartilage 
Table 2 The top 10 HTO research papers with the most citation frequency

\begin{tabular}{|c|c|c|c|c|c|c|c|}
\hline Rank & Topic & First author & Year & Journal & $\begin{array}{l}\text { Impact } \\
\text { factor }\end{array}$ & Citations & Major conclusion \\
\hline 1 & $\begin{array}{l}\text { OARSI recommendations for the } \\
\text { management of hip and knee } \\
\text { osteoarthritis, part II: OARSI } \\
\text { evidence-based, expert } \\
\text { consensus guidelines }\end{array}$ & Zhang, W. & 2008 & $\begin{array}{l}\text { Osteoarthritis and } \\
\text { Cartilage }\end{array}$ & 4.879 & 1569 & $\begin{array}{l}\text { They developed } 25 \text { expert consensus } \\
\text { recommendations for the treatment } \\
\text { of osteoarthritis of the hip and knee } \\
\text { (OA) }\end{array}$ \\
\hline 2 & $\begin{array}{l}\text { Human autologous culture } \\
\text { expanded bone marrow } \\
\text { mesenchymal cell transplantation } \\
\text { for repair of cartilage defects in } \\
\text { osteoarthritic knees }\end{array}$ & Wakitani, S & 2002 & $\begin{array}{l}\text { Osteoarthritis and } \\
\text { Cartilage }\end{array}$ & 4.879 & 631 & $\begin{array}{l}\text { This procedure highlights the } \\
\text { availability of autologous culture } \\
\text { expanded bone marrow } \\
\text { mesenchymal cell transplantation for } \\
\text { the repair of articular cartilage } \\
\text { defects in humans }\end{array}$ \\
\hline 3 & $\begin{array}{l}\text { Improvements in surgical } \\
\text { technique of valgus high tibial } \\
\text { osteotomy }\end{array}$ & Lobenhoffer, P & 2003 & $\begin{array}{l}\text { Knee Surgery Sports } \\
\text { Traumatology } \\
\text { Arthroscopy }\end{array}$ & 3.149 & 270 & $\begin{array}{l}\text { They present four technical } \\
\text { modifications of high tibial } \\
\text { osteotomy which improve its safety } \\
\text { and reproducibility }\end{array}$ \\
\hline 4 & $\begin{array}{l}\text { Treatment of anterior cruciate } \\
\text { ligament injuries, part I }\end{array}$ & Beynnon, BD & 2005 & $\begin{array}{l}\text { American Journal } \\
\text { of Sports Medicine }\end{array}$ & 6.093 & 260 & $\begin{array}{l}\text { They review the treatment of anterior } \\
\text { cruciate ligament injuries }\end{array}$ \\
\hline 5 & $\begin{array}{l}\text { Joint injury causes knee } \\
\text { osteoarthritis in young adults }\end{array}$ & Roos, EM & 2005 & $\begin{array}{l}\text { Current Opinion in } \\
\text { Rheumatology }\end{array}$ & 3.851 & 249 & $\begin{array}{l}\text { Knee injury prevention, rehabilitation } \\
\text { after knee injuries, regular exercise, } \\
\text { maintaining body weight, and a } \\
\text { changed locomotion pattern may } \\
\text { prevent osteoarthritis initiation and } \\
\text { progression in young adults }\end{array}$ \\
\hline 6 & $\begin{array}{l}\text { Control of frontal plane knee } \\
\text { laxity during gait in patients with } \\
\text { medial compartment knee } \\
\text { osteoarthritis }\end{array}$ & Lewek, MD & 2004 & $\begin{array}{l}\text { Osteoarthritis and } \\
\text { Cartilage }\end{array}$ & 4.879 & 219 & $\begin{array}{l}\text { The presence of medial laxity in } \\
\text { patients with knee OA is likely } \\
\text { contributing to the altered gait } \\
\text { patterns observed in those with } \\
\text { medial knee OA }\end{array}$ \\
\hline 7 & $\begin{array}{l}\text { TomoFix: a new LCP-concept for } \\
\text { open wedge osteotomy of the } \\
\text { medial proximal tibia-early } \\
\text { results in } 92 \text { cases }\end{array}$ & Staubli, AE & 2003 & $\begin{array}{l}\text { Injury-International } \\
\text { Journal of the Case } \\
\text { of the Injured }\end{array}$ & 1.834 & 214 & $\begin{array}{l}\text { A new fixation device (TomoFix (TM)) } \\
\text { with an adapted surgical technique } \\
\text { allows stable fixation of the } \\
\text { osteotomy without the need to fill } \\
\text { the osteotomy gap with bone grafts }\end{array}$ \\
\hline 8 & $\begin{array}{l}\text { Meniscal allograft transplantation: } \\
\text { long-term clinical results with } \\
\text { radiological and magnetic } \\
\text { resonance imaging correlations }\end{array}$ & $\begin{array}{l}\text { Verdonk, Peter } \\
\text { C. M. }\end{array}$ & 2006 & $\begin{array}{l}\text { Knee Surgery Sports } \\
\text { Traumatology } \\
\text { Arthroscopy }\end{array}$ & 3.149 & 212 & $\begin{array}{l}\text { Long-term results after viable } \\
\text { meniscus allograft transplantation are } \\
\text { encouraging in terms of pain relief } \\
\text { and improvement of function }\end{array}$ \\
\hline 9 & $\begin{array}{l}\text { Tibial osteotomy for the treatment } \\
\text { of varus gonarthrosis—-survival } \\
\text { and failure analysis to twenty-two } \\
\text { years }\end{array}$ & Sprenger, TR & 2003 & $\begin{array}{l}\text { Journal of Bone and } \\
\text { Joint Surgery American } \\
\text { Volume }\end{array}$ & 4.716 & 206 & $\begin{array}{l}\text { There is a role for tibial osteotomy, as } \\
\text { an alternative to total knee } \\
\text { arthroplasty, in patients who are less } \\
\text { than } 60 \text { years old }\end{array}$ \\
\hline 10 & $\begin{array}{l}\text { Decreased knee adduction } \\
\text { moment does not guarantee } \\
\text { decreased medial contact force } \\
\text { during gait }\end{array}$ & $\begin{array}{l}\text { Walter, } \\
\text { Jonathan P. }\end{array}$ & 2010 & $\begin{array}{l}\text { Journal of Orthopaedic } \\
\text { Research }\end{array}$ & 3.043 & 199 & $\begin{array}{l}\text { Future studies that evaluate the } \\
\text { effectiveness of gait modifications for } \\
\text { offloading the medial compartment } \\
\text { of the knee should consider the } \\
\text { combined effect of these two knee } \\
\text { moments }\end{array}$ \\
\hline
\end{tabular}

restoration techniques has a good medium-term effect, but the long-term effect remains to be further studied $[4,21,22]$. Technological innovation and long-term efficacy research may be the future development direction in this aspect.

Cluster 3 is "Animal experimental research." The basic research of HTO is mainly focused on animal experiments. Ziegler et al. concluded that open wedge valgus HTO is a safe surgical method through experiments on sheep [23]. In addition, Franklin et al. found that platelet-rich plasma could not promote bone fracture healing in dogs undergoing HTO [24]. Although this kind of study accounts for less, it is an important part of the HTO research.

Cluster 4 relates to "Study on bone union and plate fixation at osteotomy." Proper plate fixation is a key factor in the success of HTO operation [25]. Appeared in recent years, many are distinctive of fixed steel plate, such as TomoFix plate, iBalance, Puddu plate, and Contour Lock [26]. Among them, TomoFix plate is widely 

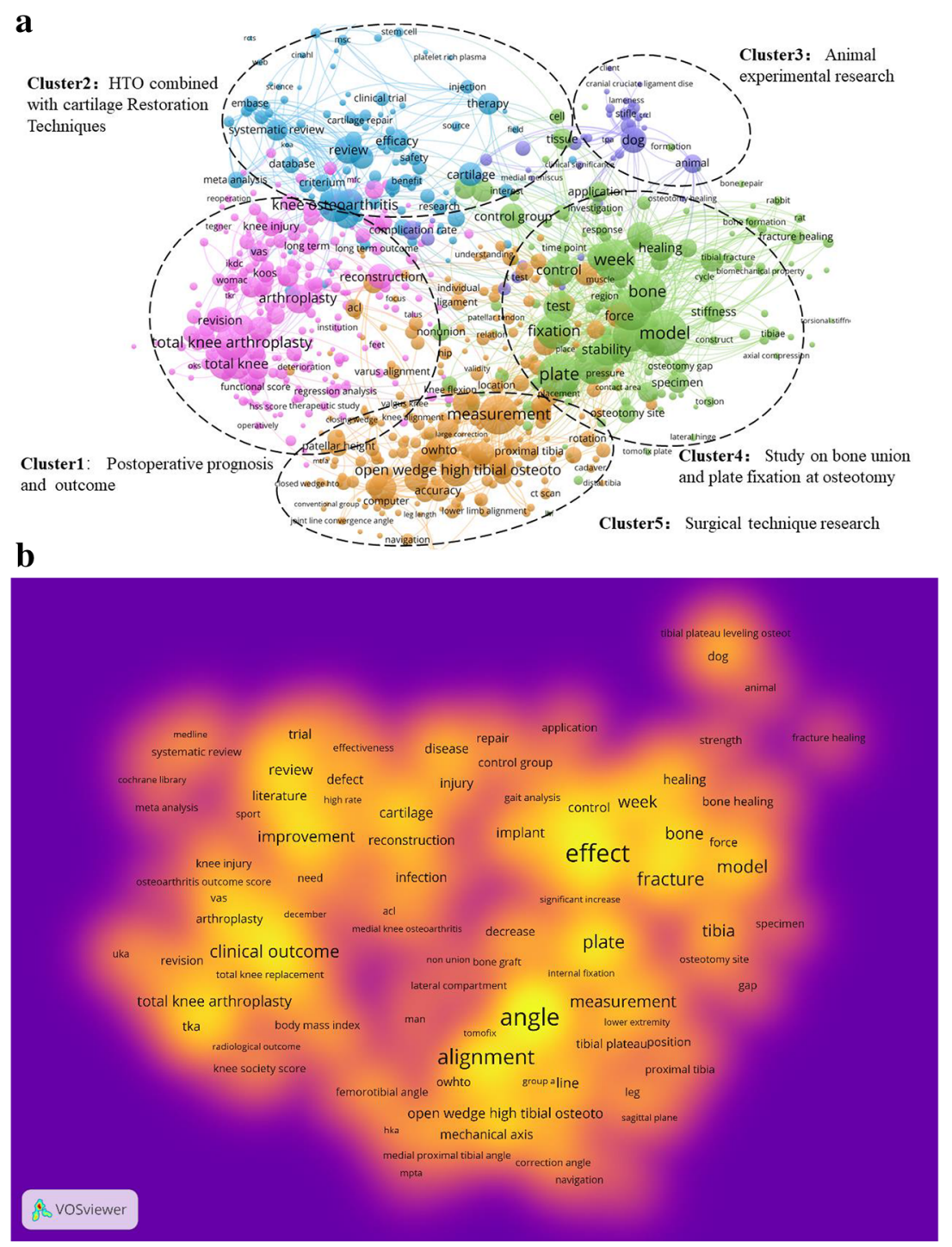

c

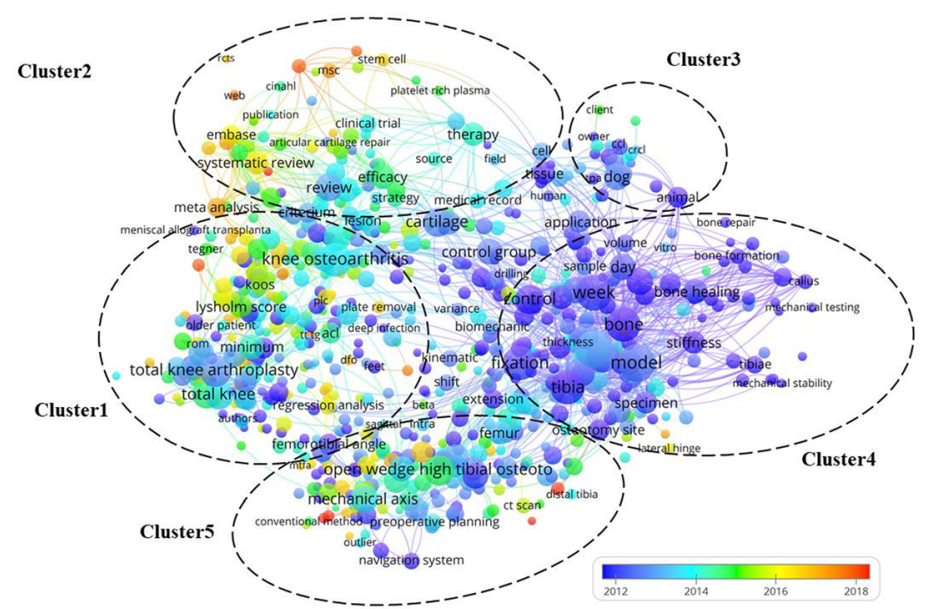

Fig. 4 (See legend on next page.) 
(See figure on previous page.)

Fig. 4 Co-occurrence analysis of HTO. a Mapping of keywords in the research area. The size of the points represents the frequency of appearance, and the keywords are divided into five clusters. $\mathbf{b}$ Heat map of keywords according to the mean frequency of appearance. c Overlap visualization diagram of color variation with the time axis (2012-2018); blue and purple nodes appear later than yellow and red nodes, meaning that red and yellow nodes are hot keywords

used. TomoFix plate is designed based on the principle of locking compression plate (LCP), which is strongly fixed by 4 screws at the distal and proximal ends of the osteotomy, so that patients can carry weight and exercise earlier [27]. However, fixation methods need to be tailored because of individual differences (body weight, bone mass, proximal tibial length, tibial shape). Therefore, we speculate that the individual design of the steel plate will become a hot research topic in the future. Nonunion at the end of osteotomy is mainly occurred in medial opening wedge high tibial osteotomy (MOWHTO) but rarely in lateral closing wedge high tibial osteotomy (LCWHTO). Because of the wedge-shaped defect in the medial osteotomy after MOWHTO distraction, whether bone graft is needed or not is still controversial. Most scholars hold the view that bone grafting depends on the spacing of distraction, the angle of correction, whether there is a "hinge" fracture, and the factors that affect the nonunion of the fracture [28-30].

Cluster 5 relates to "Surgical technique research." At present, there are two main surgical methods for HTO: LCWHTO and MOWHTO. LCWHTO has reliable postoperative stability, allows for early weight-bearing, and does not require bone grafting. Nevertheless, there are also disadvantages such as a high probability of peroneal nerve injury (3.3 11.9\%) and unfavorable TKA when the orthotic angle is large [31]. By contrast, MOWHTO has advantages such as the ability to correct coronal and sagittal positions, the minimal possibility of injury to the common peroneal nerve, and simple intraoperative operation. But the nonunion or delayed union of the fracture mentioned above is one of its major defects [32]. OWHTO can more effectively correct the deformity of the force line and meet the needs of young patients by comparing comprehensively these two procedures. Therefore, more attention will perhaps be paid to in the future.

Based on Fig. 4c, it can be noted that most of the red and yellow keywords are distributed in cluster 1, cluster 2 , and cluster 5 . This indicates that major developments will take place in HTO combined with cartilage restoration techniques, postoperative prognosis and outcome, and surgical technique research in the future.

Although this study provides a comprehensive bibliometric analysis of HTO and the prediction of hot research directions, we believe that there are still the following limitations. First of all, it is restricted by the use of language as only English publications are included. Secondly, we only use WOS database to retrieve data, and several literatures may be omitted. In addition, there is a certain deviation between the results of our bibliometric analysis and the actual results, by reason of the continuous updating of the online database.

\section{Conclusion}

This study reveals the global status and hot direction of HTO. There will be an increasing number of HTO articles published according to the development trend in recent years. The USA has contributed the most in the field of HTO up to now. We speculate that HTO combined with cartilage restoration techniques, postoperative prognosis and outcome, and surgical technique research will may be the future hot directions in HTO field.

\section{Abbreviations \\ KOA: Knee osteoarthritis; HTO: High tibial osteotomy; WOSCC: The Web of Science Core Collection database; MOWHTO: Medial opening wedge high tibial osteotomy; LCWHTO: Lateral closing wedge high tibial osteotomy; TKA: Total knee arthroplasty; UKA: Unicompartmental knee arthroplasty}

\section{Acknowledgments}

One of the first authors (Haitao Zhang) want to show heartedly thanks to his friend Yan LV, who provided much help for the grammar expression.

\section{Authors' contributions}

Conceptualization: Haitao Zhang and Yirong Zeng. Literature search: Haitao Zhang, Yinuo Fan, and Jiahao Li. Data extraction: Rui Wang and Yijin Li. Software: Wenjun Feng and Jinlun Chen. Formal analysis: Peng Deng and Xinyu Qi. Writing: Haitao Zhang. Manuscript revision: Jianchun Zeng and Pengcheng Ye. The authors read and approved the final manuscript.

\section{Funding}

This work was supported by the High-Level Hospital Construction Project of the First Affiliated Hospital of Guangzhou University of Chinese Medicine (211010010722) in the form of covering the consultation fees of data statistical analysis. Yirong Zeng received scientific funding from the High-Level Hospital Construction Project of the First Affiliated Hospital of Guangzhou University of Chinese Medicine, and the grant number is 211010010722.

\section{Availability of data and materials}

The datasets used and/or analyzed during the current study are not publicly available due to feasibility but are available from the corresponding author on reasonable request.

\section{Ethics approval and consent to participate}

Not applicable.

\section{Consent for publication}

Not applicable

\section{Competing interests}

The authors declare that they have no competing interests.

\section{Author details}

${ }^{1}$ The First Clinical Medical School, Guangzhou University of Chinese Medicine, Jichang Road 12\#, District Baiyun, Guangzhou, Guangdong, China. ${ }^{2}$ Department of Orthopaedics, The First Affiliated Hospital of Guangzhou 
University of Chinese Medicine, Jichang Road 16\#, District Baiyun, Guangzhou 510405, Guangdong, China.

\section{Received: 4 September 2020 Accepted: 1 October 2020}

\section{Published online: 09 November 2020}

\section{References}

1. Bąkowski $P$, et al. Autologous adipose tissue injection versus platelet-rich plasma (PRP) injection in the treatment of knee osteoarthritis: a randomized, controlled study - study protocol. BMC Musculoskelet Disord. 2020;21(1):314.

2. Hermann W, Lambova S, Mullerladner U. Current treatment options for osteoarthritis. Curr Rheumatol Rev. 2017;14(2):108-16.

3. Wright JM, et al. High tibial osteotomy. J Am Acad Orthop Surg. 2005;13(4): 279-89.

4. Smith JO, Wilson AJ, Thomas NP. Osteotomy around the knee: evolution, principles and results. Knee Surg Sports Traumatol Arthrosc. 2013;21(1):3-22.

5. Cantin $\mathrm{O}$, et al. The role of high tibial osteotomy in the treatment of knee laxity: a comprehensive review. Knee Surg Sports Traumatol Arthrosc. 2015; 23(10):3026-37.

6. Palthe AFYW, et al. Survival and functional outcome of high tibial osteotomy for medial knee osteoarthritis: a 10-20-year cohort study. Eur Orthop Surg Traumatol. 2018;28(7):1381-9.

7. Lee DC, Byun SJ. High tibial osteotomy. Knee Surg Related Res. 2012; 24(2):61-9.

8. Bonasia DE, et al. High tibial osteotomy. Curr Rev Musculoskelet Med. 2014; 7(4):292-301.

9. Seil $R$, et al. The rapid evolution of knee osteotomies. Knee Surg Sports Traumatol Arthrosc. 2013;21(1):1-2.

10. Bornmann $L$, Leydesdorff $L$. Scientometrics in a changing research landscape: bibliometrics has become an integral part of research quality evaluation and has been changing the practice of research. EMBO Rep. 2014;15(12):1228-32

11. Chiu WT, Ho YS. Bibliometric analysis of tsunami research. Scientometrics. 2007;73(1):3-17

12. Synnestvedt MB, Chen $C_{1}$ Holmes JH. CiteSpace II: visualization and knowledge discovery in bibliographic databases. AMIA Annu Symp Proc. 2005:2005:724-8.

13. McNamara l, et al. High tibial osteotomy: evolution of research and clinical applications--a Canadian experience. Knee Surg Sports Traumatol Arthrosc 2013;21(1):23-31.

14. Hui $C$, et al. Long-term survival of high tibial osteotomy for medial compartment osteoarthritis of the knee. Am J Sports Med. 2011;39(1):64-70.

15. A WD, Robertsson O, Lohmander LS. High tibial osteotomy in Sweden, 1998-2007: a population-based study of the use and rate of revision to knee arthroplasty. Acta Orthop. 2012;83(3):244-8.

16. Niinimäki T, et al. Survivorship of high tibial osteotomy in the treatment of osteoarthritis of the knee: Finnish registry-based study of 3195 knees. Bone Joint Surg Br. 2012;94(11):1517-21.

17. Ekeland A, et al. Good functional results following high tibial openingwedge osteotomy of knees with medial osteoarthritis: a prospective study with a mean of 8.3 years of follow-up. Knee. 2017;24(2):380-9.

18. Chen $X$, et al. Higher risk of revision in total knee arthroplasty after high tibial osteotomy: a systematic review and updated meta-analysis. BMC Musculoskelet Disord. 2020;21(1):153.

19. Kahlenberg CA, et al. Analysis of outcomes for high tibial osteotomies performed with cartilage restoration techniques. Arthroscopy. 2017;33(2): 486-92.

20. Rossi R, Bonasia DE, Amendola A. The role of high tibial osteotomy in the varus knee. J Am Acad Orthop Surg. 2011:19(10):590-9.

21. Kim MK, et al. No correction angle loss with stable plates in open-wedge high tibial osteotomy. Knee Surg Sports Traumatol Arthrosc. 2015;23(7): 1999-2006.

22. Rönn K, et al. Current surgical treatment of knee osteoarthritis. Arthritis. 2011:2011:454873.

23. Ziegler $\mathrm{R}$, et al. Effect of open wedge high tibial osteotomy on the lateral tibiofemoral compartment in sheep. Part II: standard and overcorrection do not cause articular cartilage degeneration. Knee Surg Sports Traumatol Arthrosc. 2014:22(7):1666-77.

24. Franklin SP, Burke EE, Holmes SP. The effect of platelet-rich plasma on osseous healing in dogs undergoing high tibial osteotomy. PLoS One. 2017 12(5):e0177597.
25. Liu $X$, et al. High tibial osteotomy: review of techniques and biomechanics. J Healthc Eng. 2019;2019:8363128.

26. Diffo Kaze A, et al. Mechanical strength of a new plate compared to six previously tested opening wedge high tibial osteotomy implants. J Exp Orthop. 2019;6(1):43

27. MacLeod AR, et al. The effect of plate design, bridging span, and fracture healing on the performance of high tibial osteotomy plates: an experimental and finite element study. Bone Joint Res. 2018;7(12):639-49.

28. Aryee $\mathrm{S}$, et al. Do we need synthetic osteotomy augmentation materials for opening-wedge high tibial osteotomy. Biomaterials. 2008;29(26):3497-502.

29. Zorzi AR, et al. Opening-wedge high tibial osteotomy with and without bone graft. Artif Organs. 2011;35(3):301-7.

30. El-Assal MA, et al. Opening-wedge high tibial osteotomy without bone graft. Knee Surg Sports Traumatol Arthrosc. 2010;18(7):961-6.

31. Sun $\mathrm{H}$, et al. Comparison between closing-wedge and opening-wedge high tibial osteotomy in patients with medial knee osteoarthritis: A systematic review and meta-analysis. J Knee Surg. 2017:30(2):158-65.

32. Duivenvoorden T, et al. Adverse events and survival after closing- and opening-wedge high tibial osteotomy: a comparative study of 412 patients. Knee Surg Sports Traumatol Arthrosc. 2017;25(3):895-901.

\section{Publisher's Note}

Springer Nature remains neutral with regard to jurisdictional claims in published maps and institutional affiliations.
Ready to submit your research? Choose BMC and benefit from:

- fast, convenient online submission

- thorough peer review by experienced researchers in your field

- rapid publication on acceptance

- support for research data, including large and complex data types

- gold Open Access which fosters wider collaboration and increased citations

- maximum visibility for your research: over $100 \mathrm{M}$ website views per year

At $\mathrm{BMC}$, research is always in progress.

Learn more biomedcentral.com/submissions 